\title{
Providing Gainful Employment for Emotionally Disabled Persons*
}

\author{
$A$ model of vocational integration \\ ERWIN SEYFRIED, Freie Universität Berlin, Psychologisches Institut WE3, Habelschwerdter Allee 45, D-1000 \\ Berlin 33
}

With this contribution I would like to give a general account of new attempts in the Federal Republic of Germany (FRG) to provide suitable jobs for emotionally handicapped people. It concerns jobs in enterprises on the general labour market which have been especially created for the emotionally handicapped in order to make social access possible for them. Just as certain physical changes in environment, transport, building etc. allow social access to public life for the physically disabled, the above mentioned group of people need certain social places which take their special needs into account. ${ }^{1}$

When these enterprises came into existence in the late seventies, it became more and more difficult for them to find employment because of the increase in general unemployment. Thus the workshops for the handicapped, whose proper function was vocational training, became more and more frequently a dead-end. In addition, these institutions for the emotionally disabled were hardly acceptable for various reasons, e.g. status, pay, anonymity. In response to these social problems, the so-called self-help enterprises came into being on the initiative of mostly independent groups and institutions in the psychiatric sector. However, most of these initiatives have been launched directly by psychiatric clinics or related bodies but the firms themselves are institutionally independent from the clinics. The jobs in the projects are as a rule intended for patients of these clinics, e.g. following rehabilitation in work therapy. But these people may also come from sheltered workshops, via centres of vocational training or via institutions on an outpatient basis. Therefore all initiatives are integrated into the existing supporting network but at the same time are institutionally independent. All workers possess a more or less long psychiatric career. Some of them have had stays in institutions lasting for more than 10 years. A larger proportion of workers has been in and out of clinics over the years. Their common experience is not being able to find an appropriate job in the existing labour market. The general term 'emotionally disabled persons' represents the range of psychiatric diagnoses across the full spectrum, i.e. amongst the workers there are people both with chronically psychotic disturbances and those with severe neurotic peculiarities of behaviour.

* Contribution to the Second European Conference on Research in Rehabilitation

\section{Field survey}

1. Quantity of projects

Altogether there are 25 of these projects in the FRG today. Nineteen provide employment which concurs with wages regulations. (This is employment where standard wages are paid and contributions to social, health and unemployment insurance as well as wage tax are deducted.) Six projects only provide jobs with additional income. These are jobs for people who live primarily with public support such as social assistance or retirement pension, wages play only a secondary role as additional income. Eight enterprises offer both kinds of employment, that is both jobs with standard wages and jobs that provide additional income.

2. Quantity of jobs

Altogether there are 256 jobs of that kind in the FRG at present: $49 \%$ (127) of these jobs are based on standard wages; $51 \%$ (129) offer only part-time jobs with additional income.

Taking into account also that a very high percentage of standard employment concerns part-time jobs only, the following can already be concluded: in order to provide occupational integration of emotionally disabled persons, jobs are evidently needed which are suitable for the various conditions (for example retirement), needs and abilities of these persons regarding flexibility of working hours.

\section{Nature of employment}

The distribution of employment according to available content of labour is shown in the Table.

As suggested by the Table, employment for additional income predominates in agricultural and trade establishments. I presume that this is not only the result of the needs of the employees, but stems also from the generally diffcult economic situation of agriculture and trade in the FRG. In the services sector and in industrial production the proportion is almost equal.

The very high share of the services sector must come as a surprise however, especially since as a rule emotionally disabled persons are regarded as not suitable for this kind of employment and are excluded from this sector by the traditional supply of existing workshops for the handicapped. Therefore we may say that the firms and enterprises for the emotionally disabled have made the services sector accessible for this group of people.

The importance of this aspect becomes clear when we examine the jobs offered from the point of view of the extent to which they give the opportunity of contact with the 
TABLE

Distribution of employment

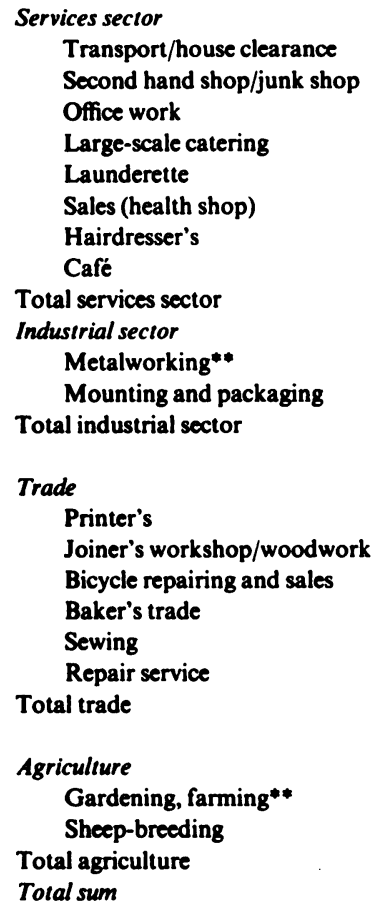

-Those figures in brackets concern employment for additional income.

** Changing orders do not allow detailed classification.

client, that is, the normal citizen. Since some of the jobs from the trade sector are suitable as well, the proportion amounts to approximately $30 \%$. As results of participating observation indicate, possibilities of contact with clients entail a considerable effect of normalisation and gain of status.

A relatively high proportion, about $23 \%$ of the jobs, (that is 29/30), is set in comprehensive working processes where a product is made from start to finish in a clear and meaningful working course. In most enterprises spontaneous change of job within the firm can be agreed upon also.

4. Financing of enterprises

In the following I differentiate according to initial costs, current costs and costs for attending personnel.

(a) Initial financing. The initial investments originate mostly from public subsidy; the establishment of jobs for the handicapped is publicly promoted in the Federal Republic. Part of the funds originates from foundations or private contributors however. In very rare cases loans were used for financing so that as a rule there are hardly any charges for interest or repayment for the enterprises. (b) Current costs. The above-mentioned fact is of advantage for the projects since more scope is left to achieve their purpose of making a big enough profit margin to cover the entire current costs for wages, raw materials, materials etc. on an independent scale. The majority of the projects meet their own claim. If this is not the case external assistance is claimed in order to subsidise wages, for example from the social funds of the European Community.

(c) Costs for attending personnel. The costs for the attending personnel are not obtained but then this was not the projects' target. The additional requirements for personnel are usually covered by public subsidies.

5. Integration aims

The aim of the enterprises and projects is to provide employment for the emotionally handicapped which corresponds with their needs, possibilities and abilities. The duration of employment is basically unrestricted. Even in the case of possible emotional crisis entailing a prolonged in-patient treatment the job is saved for the person concerned. The comparatively low figure of fluctuation underlines the importance of a secure, permanent job meeting their requirements.

\section{Qualitative results}

I would like to present the qualitative data which were gained from structured interviews and by participating observation.

\section{Status}

A permanent job in such an enterprise is connected with a considerable gain in status for the employee. On the one hand this is linked with the employee role: one defines oneself as worker, no longer as patient or handicapped person ${ }^{2}$. On the other hand it is linked with daily co-operation with non-handicapped persons. Furthermore, the environment is much less stigmatised by a ghetto atmosphere than the workshops for the handicapped. This becomes apparent in the following interview extract:

"What did you gain by working here so far?".

"A boost to my ego really, being able to work in a normal enterprise again, and not only in the workshop for the handicapped..."

"What exactly do you mean by boost to my ego?"

"You really are somebody, amongst friends, too. And maybe find a girl again. Before, I didn't dare look for one, being in the workshop. For a start because of money and secondly because I was at the workshop for the handicapped...".

2. Wages

The empirical analyses show that apart from the question of status the amount of pay is an important factor for handicapped employees. Another interview extract:

"What does your job mean to you?"

"That I can afford my own place, that I may invite whoever I want to and whenever I want to. . . Before I had I 50 Deutschmarks every fortnight. From this I had to hand over $50 \mathrm{DM}$ to my mother because I stayed at her place. What can you do with 100 Deutschmarks? It's no fun to look at your own four walls all the time, never to leave the house." 
The average income per month cannot be determined exactly, since the various arrangements of working hours and pay do not permit such a generalisation. The figures vary round about DM 900 , net per month, taking a working week of 30 hours as a basis. They may reach up to a monthly income of DM 1.400, net for a working week of 38.5 hours. Usually the ideas of emotionally disabled persons concerning the amount of their pay by far exceeds the extent of their actual capability.

\section{Contents of labour}

Seen from the point of view of labour content, clearly structured working processes and definitely structured functions prove to be helpful. The emotionally handicapped often feel overburdened by tasks involving complex competence. The positive importance of comprehensive working processes was not acknowledged by the analysis. On the contrary, it was conspicuous that workers take little interest in the actual product and have an indifferent attitude towards the various activities. "I don't care where I work" would be a typical statement. The actual job is primarily of importance from the point of view of its social context: "Who do I work with there?" is the question of interest. In those cases where a rotation principle concerning the available jobs is possible, a change is also made from the point of view of social contacts. Such a change takes place frequently in order to surmount current problems of presence or distance and to settle that amount of social contact that the person concerned is capable of having just then.

\section{Worker-participation}

In almost all enterprises the workers are offered extensive possibilities for worker-participation in the light of internal decisions. Experience shows, however, that these possibilities are rarely taken advantage of. Coming to an important decision seems to overburden the mentally handicapped. From an interview:

"I can't participate because I don't know the first thing about it."

"How could that be changed?"

"Not at all, because I. . ., when I am working I don't feel the need to do big business on top of it all and to carry responsibility. If something went wrong I really wouldn't be able to cope with it."

5. Co-operation

The analyses of the qualitative data indicate that the cooperative and social dimension of work is of the most vital importance for the emotionally disabled. This is expressed in statements underlining repeatedly the importance of social conditions and social relations between the workers. For many of them the working-place itself also becomes some kind of emotional home at certain times. This is shown, for example, by the fact that the workers come to their place of work even on their days off. From an interview:

"We get together here, have a chat after work, stay around a little longer and later give the others a call... Outside we keep in touch, too. At other jobs I used to finish work and left because I didn't want to know anything about the other people. But here I really want to find out things."
This feeling of belonging appears mainly when the emotionally disabled person is respected despite his restricted capabilities. This acceptance relieves the handicapped of his burden of having to comply with extreme expectations.

The missing constancy of performance and fluctuation of achievement level are normally compensated for by the non-handicapped fellow workers. In this respect they are mostly in some kind of supervisory position towards the handicapped. Experience shows that with regard to this dimension of work, explicit distribution of roles facilitates orientation of the person concerned regarding structuring and grasping of the working situation. ${ }^{3}$

Interpersonal problems and tension between the handicapped and the non-handicapped arise when such fluctuation of achievement can no longer be interpreted as an expression of being handicapped but appears as voluntary irresponsibility or lack of consideration. ${ }^{4}$ Continuous dealing with the extent and the acceptance of the handicap in question is required from all persons concerned. This is not only of importance in the interest of better co-operation between the handicapped and the non-handicapped, but also because the acceptance of their handicap and their personality is closely attached to the sense of social belonging for the handicapped. This process is encouraged by the assistance of psychological and social specialists.

\section{Conclusion}

The field survey indicates that the number of such models of employment for the emotionally handicapped has steadily increased. These models fill an important gap between normal businesses in the general labour market and traditional workshops for the handicapped.

Because of the importance of the social dimension of work the vocational and social integration into small and clear units with continual social relations seems to be particularly appropriate for the emotionally disabled. It is at any rate much more appropriate than integration into an anonymous large-scale institution. In particular, through co-operation with the non-handicapped, the vocational integration can be linked with the social one. However, it appears necessary to deal with arising problems of cooperation through psychological and social care at the job.

\section{References}

${ }^{1}$ BENNETt, D. (1985) Die Bedeutung von Arbeit in der Behandlung und Rehabilitation chronisch psychotisch kranker Menschen. In Im Schatten der Wende (eds. Keupp, Kleiber \& Scholten). Tubingen: DGVT.

2 - (1975) Techniques of Industrial Therapy, Ergotherapy, and Recreative Methods. In Psychatrie der Gegenwart. Forschung und Praxis. Vol. III. (eds Kisker, Meyer et al). Berlin, Heidelberg, New York: Springer-Verlag.

${ }^{3}$ SeYfried, E. (ed.) (1985) Arbeit und seelische Gesundheit. Aus der Praxis von Beschäftigungsinitiativen und Firmen für psychisch Kranke. Bonn: Psychiatrie-Verlag.

4 \& StAdLer, P. (1985) Die Bedeutung von Arbeit für psychisch Kranke. Erfahrungen aus der Selbsthilfefirma Backstern. In Im Schatten der Wende (ibid). 